\title{
The Seminar Teaching Approach of University : Case Analysis of Master' $s$ Degree Program
}

\author{
WANG Xing-ju ${ }^{1,2}$, GAO Gui-feng ${ }^{1}$ and ZHAO Lin ${ }^{1}$ \\ 1 School of traffic and transportation, Shijiazhuang Tiedao University, Shijiazhuang, \\ Hebei 050043, China \\ 2 Traffic Safety and Control Laboratory of Hebei Province, Shijiazhuang, Heibei \\ 050043, China
}

\begin{abstract}
To explore students' learning initiative and self-learning ability, the seminar teaching approach is necessary. The seminar teaching approach can also train students' verbal ability and enhance their sense of participation. The activities can develop students to get the comprehensive ability of exploring issues. Case analysis of master's degree program is conducted. The result shows that the seminar teaching approach is better than other teaching approach. Moreover, it develops masters' abilities depending on published papers.
\end{abstract}

Keywords: Teaching Mode; Seminar; Comprehensive Ability; Case analysis.

\section{Introduction}

Seminar teaching model is a pattern of quality-oriented education for the teaching of content ${ }^{[1]}$. Seminar students in the Graduate School of the Panel, under the guidance of the professors engaged in ground-breaking research or in-depth study. Professors will discuss their reports and publish content on a regular basis.

Seminar teaching mode is applied to engineering education through surveys ${ }^{[2]}$. Through the analysis of actual cases, it focus on cultivating students' practical capability for thinking of engineering and scientific methods, broadening students' knowledge so that students can understand and master modern science, research perspectives and ways to address the problem especially in practical engineering technologies ${ }^{[3]}$. Moreover, through students' discussion of seminar subject, it also can cultivate their ability of investigate, consulting date, raising and solving problems. Seminar mode can mobilize students' initiative fully. It stimulates the students' innovative thinking and awareness ${ }^{[7]}$.

In recent years, because of the reform in quality-oriented education, Chinese university education is undergoing a profound and permanent change ${ }^{[4]}$. In the teaching reform, many new model of teaching has accumulated many successful experiences. But there are still some issues that have not been fundamentally figured out, the most prominent aspect is that the teaching model of "teaching-centered" has not changed fundamentally. Engineering has its technical characteristics in practice. It is that engineering education takes the emphasis on the classroom teaching or focus attention on the teacher mostly. It is obvious that this mode of teaching is a great deal of restraint to teachers and students. Therefore, it is a bold and meaningful attempt to combine 
engineering education with seminar teaching model ${ }^{[5]}$.

\section{Methods}

Through the establishment of the comprehensive evaluation model of teaching system ${ }^{[6]}$, it converts multiple evaluation indexes to one value. And that will be a basis for evaluating teaching quality.

According to the linear weighted method, the paper assumes $N$ parameters. They are $X_{1}, X_{2}, X_{3} \ldots . X_{\mathrm{n}}$, and their corresponding weights are $P_{1}, P_{2} \ldots P_{n}$. The final formula is:

$$
S=\sum_{i=1}^{n} X_{i} \times P_{i}
$$

The evaluation of teaching model bases on students' three achievement in three areas:

The first area is the number of students' published article $M$ : the published articles are divided into three categories: EI, SCI, meeting, their respective weights are $0.70,0.20$ and 0.10 .

The second area is graduation mark $N$ : the mark is divided into excellent (5 points), good (3points) and pass (2 points). Their corresponding weights are 0.60 , 0.25 and 0.15 .

The third is test scores $Q$ : The final exam grades are divided into four grades $\mathrm{A}(9$ points $), \mathrm{B}(8$ points $), \mathrm{C}(7$ points $), \mathrm{D}(6$ points) and $\mathrm{E}(5$ points $)$, its weight was $0.45,0.35,0.10,0.08$ and 0.02 .

The weight values of these three types: $M$ is $0.7, N$ is 0.2 and $Q$ is 0.1 .

Firstly, we prepare a same number of students from two kinds of teaching model. The paper censuses the students' achievement in three areas and calculate their achievement basing on the proportion of three areas. At last, it draws students' achievement of two models into one chart which can describe the result more directly and clearly.

The calculation formula can be given by

$$
\begin{gathered}
S=P_{1} \times \frac{\sum_{i=1}^{n} M_{X i(Y i)} \times P_{i}}{\sum_{i=1}^{n}\left(M_{X i} \times P_{i}+M_{Y i} \times P_{i}\right)} \\
+P_{2} \times \frac{\sum_{i=1}^{n} Q_{X i(Y i)} \times P_{i}}{\sum_{i=1}^{n}\left(Q_{X i} \times P_{i}+Q_{Y i} \times P_{i}\right)} \\
+P_{3} \times \frac{\sum_{i=1}^{n} N_{X i(Y i)} \times P_{i}}{\sum_{i-1}^{n}\left(N_{X i} \times P_{i}+N_{Y i} \times P_{i}\right)}
\end{gathered}
$$

$M_{X_{i}\left(Y_{i}\right)}$ - the number of published article by students in teaching patterns $X$ $(Y)$ and $P_{i}$ is their respective weights.

$Q_{X_{i}\left(Y_{i}\right)}$ - the students' test scores in teaching patterns $X \quad(Y)$ and $P_{i}$ is their respective weights.

$N_{X_{i}\left(Y_{i}\right)}$-the students' graduation mark in teaching patterns $X(Y)$ and $P_{i}$ is their respective weights.

Here the test assumes the value of seminar model to $S_{1}$, and the other as $S_{2}$, if $S_{1} \geq S_{2}$, it concludes that the seminar model is superior to the traditional education system mode, vice versa. 


\section{Analysis of case}

The test selects 24 students coming from two systems randomly. It will introduce the advance of two systems by comparing students' actual achievement. Their achievements are listed in Table 1 and Table2. Table1 lists each area achievement of the students who are educated in seminar model, and Table2 lists the achievements of students in traditional model.

Table 1. Students in Seminar model

\begin{tabular}{|c|c|c|c|c|c|}
\hline Name & EI & $\begin{array}{l}\mathrm{S} \\
\mathrm{C} \\
\mathrm{I}\end{array}$ & $\begin{array}{c}\text { Procee } \\
\text {-ding }\end{array}$ & $Q$ & $N$ \\
\hline
\end{tabular}

Fan. $\quad \begin{array}{lllll} & 3 & 2 & 5 & \text { A }\end{array}$

Wang $4 \quad \begin{array}{lllll} & 3 & 4 & \text { B } & \text { excellent }\end{array}$

Shao. $\begin{array}{llllll}5 & 3 & 4 & \text { A } & \text { excellent }\end{array}$

$\begin{array}{llllll}\text { Zhao. } & 3 & 2 & 6 & \text { A } & \text { excellent }\end{array}$

$\begin{array}{llllll}\text { Xi. } & 7 & 4 & 8 & \text { A } & \text { excellent }\end{array}$

Xue. $\begin{array}{llllll}5 & 4 & 4 & \text { B } & \text { excellent }\end{array}$

Cao. $\begin{array}{lllll}6 & 3 & 3 & \text { A } & \text { good }\end{array}$

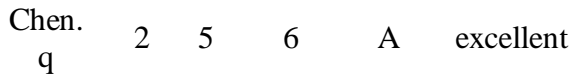

$\begin{array}{cccccc}\begin{array}{c}\text { Chen. } \\ \text { y }\end{array} & 5 & 4 & 5 & \text { A } & \text { excellent }\end{array}$

$\begin{array}{clllll}\text { Chen. } & 4 & 2 & 5 & \text { B } & \text { excellent }\end{array}$

$\begin{array}{llllll}\text { Yuan. } & 6 & 4 & 6 & \text { B } & \text { excellent }\end{array}$

$\begin{array}{llllll}\text { Zhao. } & 3 & 6 & 7 & \text { A } & \text { excellent }\end{array}$
Table 2. Students in Traditional model

\begin{tabular}{|c|c|c|c|c|c|}
\hline Name & $\begin{array}{l}\text { E } \\
\text { I }\end{array}$ & $\begin{array}{l}\mathrm{S} \\
\mathrm{C} \\
\mathrm{I}\end{array}$ & $\begin{array}{l}\text { Procee } \\
\text {-ding }\end{array}$ & $Q$ & $N$ \\
\hline Ma. & 4 & 3 & 5 & A & excellent \\
\hline Dong. & 2 & 2 & 4 & B & good \\
\hline Du. & 1 & 3 & 3 & B & excellent \\
\hline $\mathrm{Li}$. & 3 & 1 & 3 & B & good \\
\hline Liu. & 2 & 2 & 5 & B & excellent \\
\hline Ning. & 2 & 2 & 3 & $\mathrm{C}$ & good \\
\hline Tang. & 3 & 3 & 6 & B & excellent \\
\hline Wen. & 1 & 2 & 2 & A & excellent \\
\hline $\mathrm{Wu}$. & 1 & 2 & 4 & B & excellent \\
\hline Yao. & 2 & 1 & 3 & A & good \\
\hline Zhang. & 3 & 2 & 3 & $\mathrm{C}$ & excellent \\
\hline Cao. & 2 & 4 & 4 & B & good \\
\hline
\end{tabular}

$S_{1}, S_{2}$ can be obtained and

$$
S_{1}=0.6251, S_{2}=0.3749
$$

Since $S_{1} \geq S_{2}$, it draws the conclusion that the seminar model is superior to the traditional education system mode.

In order to make the results reflected more clearly and intuitively, we list them in Fig.1 and Fig.2. Fig.1 describes the students' achievements in three areas. Fig. 2 shows the final evaluation scores. $62.51 \%$ are shown that depending on the 
seminar teaching can train students' ability to learn adequately.

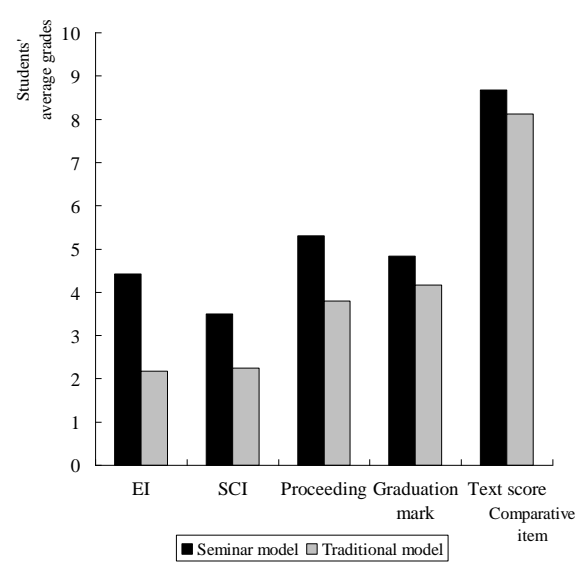

Fig.1: comparison chart between Seminar model and traditional model

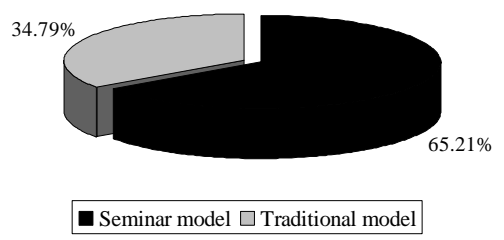

Fig.2: Pie graph of two kinds of education model

\section{Conclusion}

Through the analysis of actual cases, Seminar teaching model can cultivate students' ability of self-study and engineering practice adequately. It can also broaden students' knowledge and make students master technology in study comprehensively. This model can fully mobilize the initiative and creativity of the students in the learning process.

\section{Acknowledgments}

This research is founded by the Social Scientific and Education Research Foundation, Education Department of Hebei Province of China (Grant No: GH122053). Moreover, this research is also the project supported by the Education Research Foundation, Shijiazhuang Tiedao university of China (Grant No: 110433).

\section{References}

[1] Zhang Yue-zhong, "Modern Value of the Seminar Teaching Approch", Education and Modernization, pp. 2428, 2006.

[2] Sun Zhi-nong ${ }^{1,2}$, Qiu Xu', "Problembased Learning (PBL) in Foreign Language Educ-ation", Journal of Anhui Agricu-ltural University (Social Science Edition), Vol.18,No.6, pp. 2-3, 2009.

[3] Feng Lin-pei, "Seminar teaching mod-el based on the theory of social inter-action effects on the quality of post-graduate education", Journal of Chengdu College of Education, Vol.20,No.4, pp. 45-47, 2006.

[4] Multicultural seminar, "A new model for professional development", Muir Pers, Vol.8,No.2, pp. 18-24, 2006.

[5] Dennis O. Wackerly, William Mendenhall III, Richard L. Scheaffer, "Mathematical Statistics with Applications", Brooks/Cole, 7th internationaled, pp. 34-253, 2007.

[6] Zhang Zhong-zhan, Xie Tian-fa, Yang Zhen-hai, "Applied Mathematical Statistics", Beijing, Higher Education Press, pp. 176-184, 2011.

[7] Cong Li-xin, "Teaching method of reasonable and legitimate". Education research, vol.7, pp. 64-72, 2008. 